\title{
Correction \\ Correction: Ricceri, B. A Class of Equations with Three Solutions. Mathematics 2020, 8, 478
}

\section{Biagio Ricceri}

Citation: Ricceri, B. Correction: Ricceri, B. A Class of Equations with Three Solutions. Mathematics 2020, 8, 478. Mathematics 2021, 9, 101. https://doi.org/10.3390/math9010101

Received: 15 October 2020

Accepted: 22 December 2020

Published: 5 January 2021

Publisher's Note: MDPI stays neutral with regard to jurisdictional clai$\mathrm{ms}$ in published maps and institutional affiliations.

Copyright: () 2021 by the author. Licensee MDPI, Basel, Switzerland. This article is an open access article distributed under the terms and conditions of the Creative Commons Attribution (CC BY) license (https:// creativecommons.org/licenses/by/ $4.0 /$ ).
Department of Mathematics and Informatics, University of Catania, Viale A. Doria 6, 95125 Catania, Italy; ricceri@dmi.unict.it

The author wishes to make the following correction to this paper [1]:

Everywhere it occurs, the phrase "for every convex set $S \subseteq H_{0}^{1}(\Omega)$ dense in $H_{0}^{1}(\Omega)$ " should be replaced with "for every convex set $S \subseteq L^{\infty}(\Omega)$ dense in $L^{2}(\Omega)$ ".

Actually, thanks to $(b)$ of Theorem 2, condition (1) can be weakened to

$$
\lim _{\|x\|_{X} \rightarrow+\infty} \frac{\langle\varphi(x), y\rangle_{Y}}{I(x)}=0
$$

for all $y$ in a convex and dense set $V \subseteq Y$. Then, in the conclusion of Theorem 1 , we can

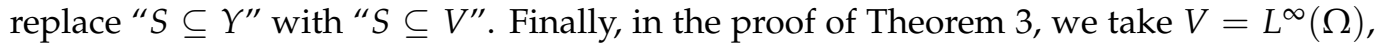
so that condition $(a)$ is actually enough to prove equality (1).

The author would like to apologize for any inconvenience caused to the readers by these changes. The changes do not affect the scientific results. The original article has been updated.

Conflicts of Interest: The author declare no conflict of interest.

\section{Reference}

1. Ricceri, B. A Class of Equations with Three Solutions. Mathematics 2020, 8, 478. [CrossRef] 